\title{
PENGUKURAN DIAMETER DAN KEDALAMAN KAWAH BULAN
}

\author{
Muhammad Hidayat*1 ${ }^{1}$, Leo Hermawan ${ }^{2}$, Riskiyan Hadi ${ }^{3}$, Hariyadi Putraga ${ }^{4}$, \\ Arwin Juli Rakhmadi Butar-Butar ${ }^{5}$ \\ 1, 2, 3,4, 5 Observatorium Ilmu Falak, Universitas Muhammadiyah Sumatera Utara \\ dayatc4@gmail.com*1, leohermawan40@gmail.com², \\ rizkiyanhadi8897@gmail.com ${ }^{3}$, hariyadiputraga@gmail.com ${ }^{4}$, \\ arwinjuli@umsu.ac.id ${ }^{5}$ \\ *Corresponding Author
}

Received 27 February 2021; revised 17 July 2021; accepted 29 July 2021.

\begin{abstract}
ABSTRAK
Penelitian ini merupakan penelitian eksperimental yang dilakukan dengan tujuan untuk mengukur secara tidak langsung diameter dan kedalaman kawah bulan yang diperoleh saat pengamatan Bulan. Penelitian ini dilakukan di Observatorium Ilmu falak Universitas Muhammadiyah Sumatera Utara dengan menggunakan teleskop William Optics Gt 102, Mounting iEQ45 Pro Kamera CCD QHY 5-II dan Canoon 600D. Penelitian ini fokus pada pengamatan kawah di Bulan, menentukan ukuran diameter dan kedalamannya pada basis foto dan perhitungan sederhana dengan beberapa penyederhanaan matematis. Berdasarkan hasil yang diperoleh dari penelitian, didapat nilai untuk diameter $(d)$ dan kedalaman $(h)$ untuk kawah bernama Tycho yaitu $d=102,95 ; h=6,6$. Copernicus $d=110,14 ; h=5,4$. Schiller $d=28,98 ; h=8,6$. Kepler $d=178,82 ; h=3,8$ dengan tingkat kesalahan pengukuran $2 \%$.
\end{abstract}

Kata kunci: bulan, diameter, kawah, kedalaman.

\begin{abstract}
This research is an experimental study conducted with the aim to measure the diameter and depth of the moon obtained when observing the Moon. This research was conducted at the Observatory of astronomy at the University of Muhammadiyah North Sumatra using the William Optics Gt 102 telescope, Mounting iEQ45 Pro CCD Camera QHY 5-II and Canoon 600D. This research focuses on observing the crater on the Moon, determining its diameter and depth based on photographs and simple calculations with some mathematical simplifications. Based on the results obtained from the study, obtained values for diameter $(d)$ and depth $(h)$ for the crater named Tycho namely $d=102.95 ; h=6.6$. Copernicus $d=110.14 ; h=5.4$. Schiller $d=28.98$; $h=8.6$. Kepler $d=178.82 ; h=3.8$ with a measurement error rate of $2 \%$.
\end{abstract}

Keywords: moon, diameter, crater, depth. 


\section{PENDAHULUAN}

Bulan merupakan salah satu objek yang menarik di langit karena penampakannya terlihat menonjol di malam hari. Permukaan bulan yang selalu tampak sama jika dilihat dari bumi disebabkan karena periode rotasi sama dengan periode revolusinya. Permukaan bulan yang nampak dari bumi terlihat banyak bercak-bercak atau bopeng yang disebut kawah yang terbentuk akibat hantaman meteor maupun benda langit lain yang jatuh di permukaan bulan (Admiranto, 2000). Bulan yang menghadap ke bumi mempunyai kurang lebih 30.000 buah kawah, yang diameternya tidak kurang dari 2 sampai 200 km (Santi, 2011).

Bulan adalah satu-satunya satelit alamiah yang dimiliki bumi. Masyarakat Romawi menyebut bulan sebagai luna. Masyarakat Yunani menamakannya dengan selene dan artemis. Karena terangnya, keberadaan bulan tentu telah diketahui sejak masa sebelum manusia mengenal tulisan. Bulan yang terlihat dari bumi tampak berwarna sangat abu-abu, tetapi variasi warna abu-abu ini bisa memberi kita informasi mengenai bulan tersebut. Bagian yang lebih terang adalah daerah yang lebih tua dan lebih tinggi dan meliputi $85 \%$ permukaan bulan, sedangkan daerah yang lebih gelap adalah daerah dataran rendah yang lebih muda umurnya (Couper \& Henbest, 2013).

Bulan tidak memiliki atsmosfer sehingga perbedaan suhu antara siang dan malam sangat tinggi. Ketika tengah hari tiba dan matahari tepat berada di atas kepala maka suhunya dapat mencapai 100 derajat celcius. Pada malam hari suhu bulan turun hingga -116 derajat celcius atau 116 di bawah nol derajat celcius. Waktu pemanasan dan pendinginan di permukaan bulan lebih lama dibanding bumi. Hal ini dikarenakan bulan menyelesaikan satu kali rotasi dalam waktu 27,3 hari di bumi.

Kawah di bulan pertama kali diamati oleh Galileo Galilei, menggunakan teleskop pertamanya pada 1609. Dia menemukan bahwa, bulan bukanlah bidang yang sempurna, tetapi memiliki gunung dan depresi seperti cangkir yang disebut sekarang dengan kawah (Grubelnik, Marhl, \& Repnik, 2018). Bulan tidak memiliki atsmosfer sehingga meteroit sekecil apapun pasti sampai ke permukaannya, itulah sebabnya jumlah kawah di bulan banyak sekali dan membuatnya tampak bopeng. Selain terdapat kawah-kawah, di bulan terdapat juga 
daerah-daerah yang bersih, tidak terlalu banyak mengalami bombardemen meteorit. Daerah-daerah ini kemudian diberi nama maria, atau mare dalam bentuk tunggal yang berarti laut. Nama-nama daerah ini misalnya Mare Transquilitatis, Mare Serenitatis, Mare Imbrium, Mare Nubium, Mare Humorum dan sebagainya (Admiranto, 2000). Saat ini, ada banyak foto dan aplikasi gratis yang umumnya tersedia, seperti Virtual Moon Atlas yang memungkinkan untuk melihat dan mengetahui lebih jauh tentang kawah di bulan. (Legrand \& Chevalley, 2015).

Ada dua tipe utama permukaan bulan. Tipe pertama, dataran tinggi bulan, merupakan permukaan yang penuh kawah dengan pegunungan-pegunungan yang sangat tua. Permukaan ini umumnya berada di bagian bulan yang membelakangi bumi (sisi jauh bulan). Tipe permukaan lainnya adalah wilayah yang sangat sedikit memiliki kawah permukaannya lebih halus dan lebih gelap dari daratan tinggi bulan. Kulit bulan berketebalan rata-rata $68 \mathrm{~km}$ dan biasanya lebih tipis di wilayah maria (rata-rata $60 \mathrm{~km}$ ). Ketebalannya bervariasi di setiap permukaan bulan, mulai dari $0 \mathrm{~km}$ di daerah Mare Crisium, hingga $107 \mathrm{~km}$ di wilayah dataran tinggi. Inti Bulan, berjejari sekitar 300-400 km (Haryadi, 2008).

Dalam penelitian ini lebih fokus tentang penentuan diameter dan kedalaman kawah bulan. Karya eksperimental sehubungan dengan studi objek astronomi sering kali membutuhkan peralatan astronomi yang mahal sehingga kurangnya karya eksperimental ini. Selain itu, membutuhkan pengetahuan tentang metode kerja yang kompleks (Grubelnik, Marhl, \& Repnik, 2018). Dalam tulisan ini, disajikan contoh karya eksperimental menggunakan teleskop. Teleskop dapat mengumpulkan cahaya lebih banyak dan juga dapat menghasilkan gambaran yang diperbesar (Robbin, 2005).

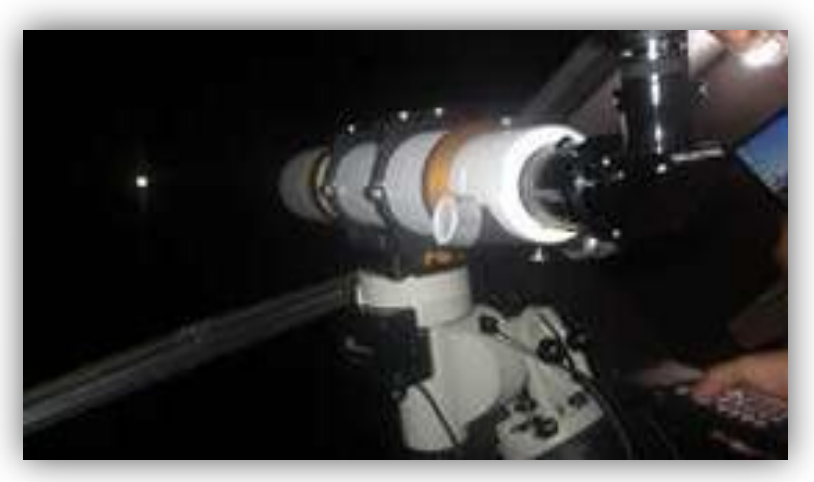

Gambar 1. Teleskop William Optics Gt 102 
Dalam penelitian kali ini, digunakan teleskop William Optics Gt 102, Mounting iEQ45 Pro Kamera CCD QHY 5-II, dan Canoon 600D. Teleskop yang digunakan saat pengamatan bulan pada malam hari seperti pada Gambar 1 . Spesifikasi lengkap dari Mounting yang digunakan disajikan pada Tabel 1.

Tabel 1. Spesifikasi Teleskop

\begin{tabular}{|c|c|}
\hline Nama & Keterangan \\
\hline Aperture & $102 \mathrm{~mm}$ \\
\hline Focal Ratio & $\mathrm{F} / 6.9$ \\
\hline Focal Length & $703 \mathrm{~mm}$ \\
\hline Objective designed & 3 elements Air-spaced with FPL53 glass \\
\hline Resolving Power & 1.13 arc " \\
\hline Limiting Magnitude & 13.9 \\
\hline Lens Shade & Retractable \\
\hline \multirow[t]{2}{*}{ Focuser } & OD 2.3" R \&P focuser , $360^{\circ}$ Rotating Camera-angle \\
\hline & Adjuster 1.25" Adapter Included \\
\hline $1.25^{\prime \prime}$ Adapter & Brass Compression Rings \\
\hline Tube Diameter & $105 \mathrm{~mm}$ \\
\hline Mounting Rings & provided \\
\hline Tube Length & 27" (689mm) Fully Retracted \\
\hline Tube Weight & $11 \mathrm{lbs} .(5.0 \mathrm{~kg})$ \\
\hline \multirow[t]{2}{*}{ Case } & High Quality Soft Case \\
\hline & (Optional accessory) \\
\hline Case Dimensions & $31 " \times 10 "$ x $13 "$ \\
\hline (W x H x D) & $(78 \mathrm{~cm} \times 25 \mathrm{~m} \times 34 \mathrm{~cm})$ \\
\hline
\end{tabular}

Dalam pengambilan citra beberapa hal yang harus diperhatikan, yaitu:

a. Mengatur ketajaman gambar objek yang diamati;

b. Menyesuaikan posisi teleskop untuk menjaga bulan terlihat;

c. Pilihan eyepiece yang tepat sesuai dengan besaran yang diinginkan;

d. Mengambil foto dengan kamera CCD dan DSLR.

Adapun tujuan penelitian ini adalah untuk mengedintifikasi permukaan kawah bulan, khususnya penentuan diameter dan kedalaman kawah bulan agar 
memberikan informasi data dari pengamat. Kajian penelitian relevan terkait penelitian kawah bulan yaitu Physical Properties of Lunar Craters, penelitian ini mempelajari hubungan antara kawah satu dengan lainnya dan juga terkait dengan posisi dan pemetaan antar kawah bulan (Joshi, Bhatt, \& Jain, 2017). Penelitian serupa berjudul Determination of the Size and Depth of Craterson the Moon yang menganalisis kemampuan siswa dalam melakukan uji coba perhitungan diameter dan kawah bulan (Grubelnik, Marhl, \& Repnik, 2018). Perbedaan yang terdapat pada penelitian sebelumnya dengan penelitian ini adalah penelitian ini lebih difokuskan pada pengukuran kedalaman dan diameter kawah bulan yang terjadi di Indonesia tepatnya di Kota Medan, Provinsi Sumatera Utara yang belum pernah diteliti sebelumnya.

\section{METODE PENELITIAN}

Metode penelitian merupakan prosedur dan langkah kerja yang digunakan dalam kegiatan penelitian mulai dari perencanaan, pengumpulan data, pengolahan data, sampai pada tahap pengambilan keputusan. Metode peneltian yang digunakan dalam penelitian ini yaitu penelitian kuantitatif dengan teknik observasi. Penelitian kuantitatif adalah suatu proses menemukan pengetahuan yang menggunakan data berupa angka sebagai alat menganalisis keterangan mengenai apa yang ingin diketahui (Kasiram, 2008). Sedangkan teknik observasi adalah teknik pengumpulan data yang bersifat khusus dan kompleks dibandingkan dengan teknik pengumpulan data yang lainnya.

Teknik pengumpulan data observasi lebih spesifik dan kompleks karena teknik pengumpulan data ini tidak hanya menjadikan manusia sebagai obyek namun juga obyek-obyek lain seperti situasi atau kondisi di suatu lingkungan (Sugiyono, 2014). Berikut dijelaskan satu-satu persatu alat-alat astronomi yang digunakan dalam pengambilan data bulan.

\section{Mounting}

Mounting atau dudukan teleskop adalah bagian dari sebuah teleskop yang menjaga teleskop tetap di tempatnya. Mounting merupakan bagian penting dari sebuah teleskop profesional. Ada dua tipe mounting yaitu alt-azimuth dan equatorial. 
Equatorial bekerja menggunakan 3 buah sumbu yaitu sumbu RA, Deklinasi dan Equator. Sedangkan mounting alt-azimuth menggunakan 2 buah sumbu yaitu sumbu $x$ atau altitude (atas bawah), dan $y$ atau azimuth (kanan kiri). Untuk pengoperasian mounting alt-azimuth jauh lebih mudah dibanding mounting equatorial. Mounting jenis equatorial yang digunakan dalam penelitian ini seperti pada Gambar 2.

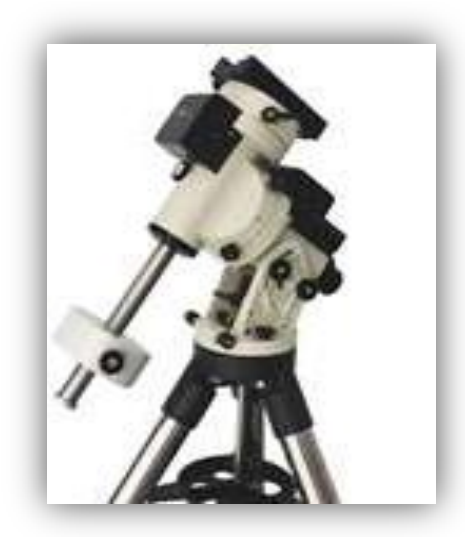

Gambar 2. iEQ45 Pro

\section{Kamera CCD QHY II-L}

Kamera CCD atau Charge Coupled Device merupakan suatu alat pencitraan untuk menkonversikan cahaya menjadi arus elektrik yang proporsional (analog). Sebuah CCD memiliki lapisan-lapisan filter yang membagi spektrum warna menjadi warna merah, hijau, biru agar bisa diproses secara digital oleh kamera.

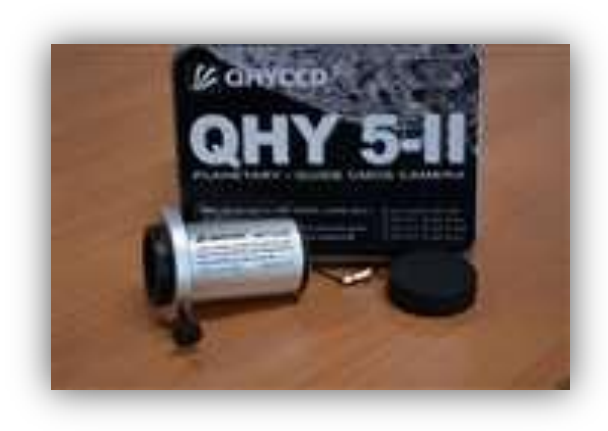

Gambar 3. CCD QHY 5-II

Teknologi yang digunakan CCD adalah teknologi yang sudah dipakai dalam waktu yang cukup lama sebagai sensor cahaya. Cara kerja sensor ini adalah 
ketika cahaya mengenai sensor, masing-masing pixel sensor menghasilkan muatan listrik yang kemudian dikonversi menjadi tegangan. Tegangan dikirim menuju chip pengkonversi sinyal analog menjadi digital (analog to digital converter A/D converter) melalui sebuah saluran dengan cara serial (seperti pada sistem register geser. Kamera CCD yang digunakan dalam penelitian ini disajikan pada Gambar 3.

\section{Kamera Canoon 600D}

Kamera digital adalah alat untuk membuat gambar dari obyek untuk selanjutnya dibiaskan melalui lensa pada sensor CCD maupun sensor BSI-CMOS (Back Side Illuminated) yang hasilnya kemudian direkam dalam format digital. Kamera digital adalah alat paling populer dalam aktivitas fotografi.

Kelebihan dari kamera digital adalah hasil gambar yang dengan cepat diketahui. Beberapa kamera digital, terutama DSLR dan high-end cameras dilengkapi fasilitas RAW yang dapat ditindaklanjuti di komputer mengunakan perangkat lunak tertentu untuk hasil terbaik, tetapi pada saat ini fasilitas Auto Mode telah menghasilkan gambar yang baik dalam format JPEG. Dalam dunia fotografi, kamera merupakan suatu piranti untuk membentuk dan merekam suatu bayangan potret pada lembaran film. Kamera DSLR yang digunakan dalam penelitian ini diberikan pada Gambar 4.

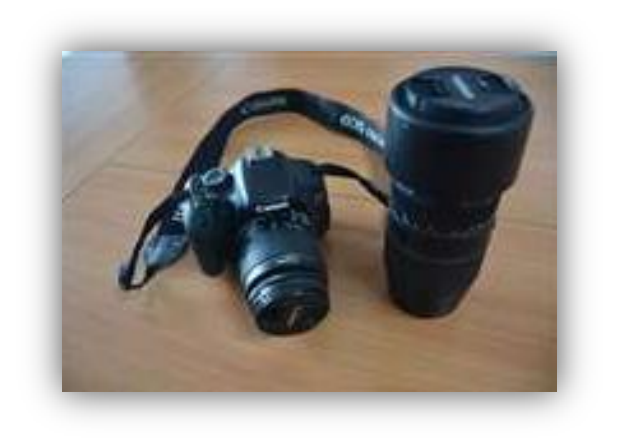

Gambar 4. Canoon 600D

\section{Software IRIS}

Iris berorientasi kepada pengolahan dan analisis ilmiah gambar/citra foto. Software IRIS mulai dikenal dalam era teknologi pada pertengahan tahun 1980an, ketika CCD kamera mulai digunakan oleh para praktisi amatir. Software ini diciptakan dalam bahasa assembly yang memiliki kemampuan untuk memproses 
gambar hingga ukuran $128 \times 128$ megapixel atau lebih. Pada penelitian ini, menggunakan software IRIS versi 5.59 yang diproduksi oleh Christian Buil pada tahun 2000 (Putraga, 2016).

\section{HASIL PENELITIAN DAN PEMBAHASAN}

\section{Pengambilan Data}

Pengamatan kawah bulan dilakukan di Observatorium Ilmu Falak, Universitas Muhammadiyah Sumatera Utara pada tanggal 16 September 2018.
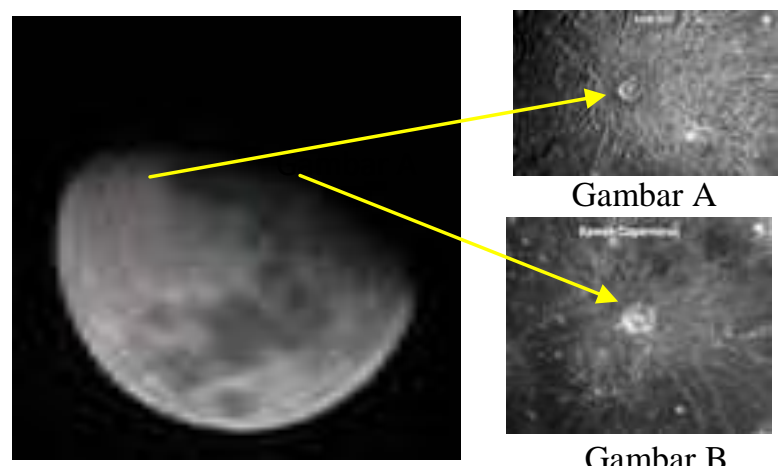

Gambar B

Gambar 5. Penentuan Diameter Kawah Bulan yang Dipilih

Gambar 5 menunjukkan posisi kawah bulan yaitu Gambar A dan Gambar B yang akan diukur kedalaman dan diameternya.

Pengamatan kedua dilakukan pada tanggal 31 Januari 2019. Gambar 6 menunjukkan posisi kawah bulan yaitu Gambar C dan Gambar D yang akan diukur kedalaman dan diameternya.
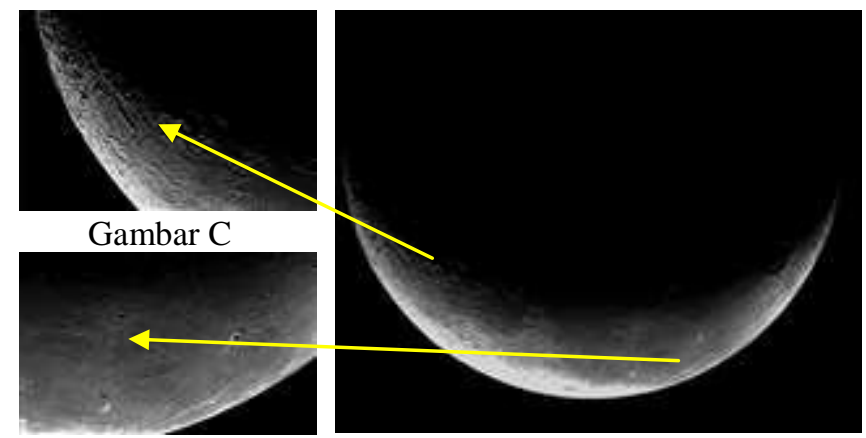

Gambar D

Gambar 6. Penentuan Diameter Kawah Bulan yang Dipilih. 


\section{Penentuan Diameter dan Kedalaman Kawah Bulan}

\section{Diameter Kawah Bulan}

Jika ingin menghitung diameter kawah, dapat digunakan perhitungan sederhana dari rasio panjang diketahui dan tidak diketahui. Prosedur yang dijelaskan secara rinci oleh Brglez lihat (Brglez M., 2012). Pada penelitian ini, diambil kawah bernama Tycho (Gambar A), Copernicus (Gambar B) Schiller (Gambar C), dan Kepler (Gambar D). Diameter bulan $2 r=3.474 \mathrm{~km}$,

$$
x=2 r \frac{x^{\prime}}{2 r^{\prime}}
$$

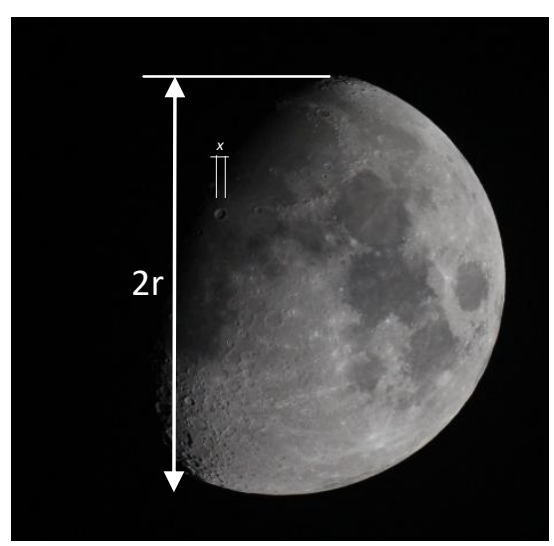

Gambar 7. Rasio Kawah Bulan

Gambar 7 menunjukkan rasio kawah bulan dalam penentuan diameter kawah bulan dengan $\frac{x^{\prime}}{2 r^{\prime}}$, rasio jumlah piksel pada layer.

Tabel 2. Hasil Perhitungan Diameter Kawah Bulan

\begin{tabular}{cc}
\hline Gambar & Diameter $(\mathbf{k m})$ \\
\hline A & 102,95 \\
B & 110,14 \\
C & 28,98 \\
D & 178,82 \\
\hline
\end{tabular}

Tabel 2 menunjukkan diameter kawah bulan pada setiap gambar yang dihitung menggunakan perhitungan sederhana dari rasio panjang diketahui dan tidak diketahui. Disimpulkan bahwa kesalahan pengukuran relatif sekitar $2 \%$. 


\section{Kedalaman Kawah}

Metode untuk menentukan kedalaman kawah didasarkan pada panjang bayangan gunung. Panjang bayangan ditentukan dengan cara yang mirip dengan penentuan diameter kawah, tetapi perlu memperbesar foto dengan tepat menentukan bagian atas (bawah) gunung (kawah) dan ujungnya bayangan. Dengan cara ini, ditentukan panjang bayangan virtual, bukan panjang sebenarnya. Untuk menentukan panjang sebenarnya dari bayangan, kita perlu memasukkan koreksi yang sesuai karena bentuk bola bulan (Kelemen et al, 2010).

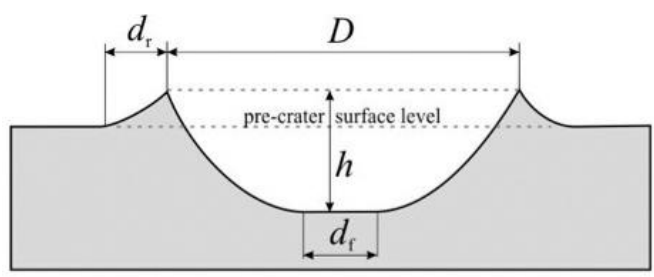

Gambar 8. Penampang Kawah

Gambar 8 menunjukkan cara perhitungan kawah bulan. Panjang bayangan beberapa kawah yang berbeda diukur dan kemudian mengikuti dari rumus berikut ini,

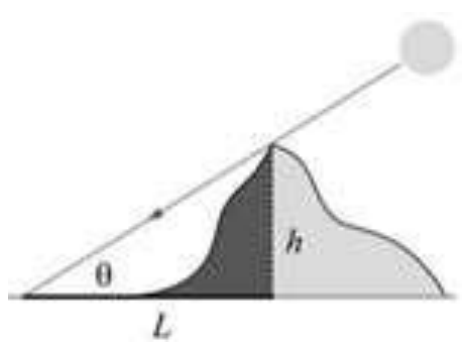

Gambar 9. Perbandingan Panjang Bayangan dan Tinggi

Gambar 9 menunjukkan sudut yang terbentuk oleh sinar matahari dan terlihat dari bayangan pada kawah bulan tersebut.

$$
h=L \tan \theta
$$

keterangan:

$h=$ tinggi

$L=$ panjang bayangan

$\theta=$ ketinggian matahari di atas cakrawala bulan 
Tabel 3. Hasil Perhitungan Kedalaman Kawah Bulan

\begin{tabular}{cc}
\hline Gambar & Kedalaman (km) \\
\hline A & 6,6 \\
B & 5,4 \\
C & 8,6 \\
D & 3,8 \\
\hline
\end{tabular}

Tabel 3 menunjukkan hasil kedalaman kawah bulan pada setiap gambarnya. Dengan menggunakan penyederhanaan ini, hasil pengukuran kedalaman kawah dalam kesalahan 2\% dibandingkan dengan data astronomi modern saat ini (Encyclopedia, 2019).

\section{SIMPULAN}

Berdasarkan hasil yang diperoleh dari penelitian, didapat nilai untuk diameter $(d)$ dan kedalaman $(h)$ untuk kawah bernama Tycho yaitu $d=102,95$; $h=6,6$. Copernicus $d=110,14 ; h=5,4$. Schiller $d=28,98 ; h=8,6$. Kepler $d=178,82 ; h=3,8$. Adapaun tingkat kesalahan pengukuran $2 \%$.

\section{UCAPAN TERIMA KASIH}

Terima kasih disampaikan kepada pimpinan Universitas Muhammadiyah Sumatera Utara yang telah memberikan fasilitas alat dan tempat di Observatorium Ilmu Falak, Universitas Muhammadiyah Surabaya untuk melakukan penelitian ini.

\section{DAFTAR PUSTAKA}

Admiranto, G. (2000). Tata surya dan alam semesta. Yogyakarta: Kanisius. Brglez, M. (2012). Velikost kraterjev na luni - računanje (The size of craters on the moon calculations). Retrieved July 6, 2021, from Wordpress: https://martinbrglez.files.wordpress.com/2012/04/velikostkraterjevnalunipdf.pdf.

Couper, H., \& Henbest, N. (2013). Ensikolpedi ruang angkasa. (G. Admiranto, Trans.) Yogyakarta: Kanisius.

Encyclopedia. (2019). Depth of moon crater. Retrieved July 6, 2021, from Britannica: https://www.britannica.com/place.

Grubelnik, V., Marhl, M., \& Repnik, R. (2018). Determination of the size and depth of craters on the moon. Center for Educational Policy Studies 
Journal, 8(1), 35-53. https://doi.org/10.26529/cepsj.322

Haryadi, R. (2008). Ensiklopedia Astronomi Jilid 3: Satelit, Asteroid dan Komet. Jakarta: Erlangga.

Joshi, M. P., Bhatt, K. P., \& Jain, R. (2017). Physical properties of lunar craters. Research in Astronomy and Astrophysics, 17(3), 24-1 - 24-16. https://doi.org/10.1088/1674-4527/17/3/24

Kasiram, M. (2008). Metodologi penelitian. Malang: UIN Malang Press.

Kelemen, M., Šomen, J. Bohinec, J., Davidović, N., \& Gomboc M. (2010). Višina gora na luni [The height of mountains on the moon]. Astronomi $v$ Kmici, 13, 8-15. Retrieved from http://www.kmica.si/wpcontent/uploads/2015/03/Bilten2010.pdf

Legrand, C., \& Chevalley, P. (2015). Virtual moon atlas 6.0 freeware. In Europian Planetary Science Congress 2015 (Vol. 10, P. 94). Retrieved from https://meetingorganizer.copernicus.org/EPSC2015/EPSC201594.pdf

Putraga, H. (2016). Astronomi dasar. Medan: CV Prima Utama.

Robbin, K. (2005). Astronomi: bengkel ilmu. Jakarta: Erlangga.

Santi, I. H. (2011). Pengukuran diameter dan kedalaman kawah Copernicus di bulan dengan menggunakan Microsoft Visio Premium $2010 \mathrm{di}$ Laboratorium Astronomi Universitas Negeri Malang. Diploma thesis. Malang: Universitas Negeri Malang.

Sugiyono. (2014). Metode penelitian kuantitatif, kualitatif, dan kombinasi (mixed method). Bandung: Alfabeta. 